\title{
Über die Reduktion
}

\section{der 0-Diäthylbenzylamincarbonsäure}

\section{und der 0-0xymethylbenzoësäure.}

\author{
Inaugural-Dissertation \\ zur
}

Erlangung der Doktorw urde

der

Hohen philosophisehen Fakultăt

der

Kgl. bayer. Ludwig-Maximilians-Universität zu München

vorgelegt von

Josef Brantl

aus Cham i. W. (Oberpfalz).

Manchen

Druck von Val. Höfling, Kapellenstrasge Nr. 3

1898. 



\section{Meinen teueren Eltern in Dankbarkeit gewidmet.}



Vorliegende Arbeit wurde im Laboratorium der Kgl. Akademie der Wissenschaften zu München auf Veranlassung und unter persönlicher Leitung des Herrn Prof. Dr. Einhorn unternommen.

Es sei mir an dieser Stelle gestattet, meinem hochverehrten Lehrer Herrn Geheimrat Prof. Dr. v. Ba eyer, sowie Herrn Prof. Dr. Einhorn für die Unterstützung, die sie stets meinen Arbeiten schenkten, meinen aufrichtigsten Dank auszusprechen. 
